\title{
Two new peacock spider species of the genus Maratus (Araneae: Salticidae: Salticinae) from south-western Australia
}

\author{
Julianne M. Waldock', Michael Duncan², Michael Doe ${ }^{3}$, Adam Fletcher ${ }^{3}$, \\ Christian $0^{\prime}$ Toole $^{3}$ and Paul Irvine ${ }^{3}$ \\ ${ }^{1}$ Collections and Research, Western Australian Museum, 49 Kew Street, Welshpool, Western \\ Australia 6106, Australia. \\ 2 School of Science, Western Sydney University, Locked Bag 1797, Penrith, New South Wales 2751, \\ Australia. \\ ${ }^{3}$ Project Maratus, https://www.facebook.com/projectmaratus/ \\ Corresponding author: julianne.waldock@museum.wa.gov.au
}

\begin{abstract}
The Australian endemic Peacock spider genus Maratus currently includes 97 species which are renowned for their elaborate courtship displays. Two new species are described from south-western Australia, M. fletcheri sp. nov. and M. harveyi sp. nov. Recently collected material has extended the range of $M$. madelineae Waldock, 2014. A brief summary of the courtship display for $M$. fletcheri sp. nov. is included.
\end{abstract}

KEYWORDS: taxonomy, morphology, south-western Western Australia

urn:Isid:zoobank.org:pub:ADD6913B-EEBE-4C24-8C02-10361EA37943

\section{INTRODUCTION}

The jumping spider genus Maratus Karsch, 1878 is endemic to the Australian region, and currently includes 97 species and one subspecies (World Spider Catalog 2020). The males of most species of Maratus have brightly coloured abdomens, with lateral flaps or fringes of coloured setae that are inflated during courtship displays (e.g. Waldock, 2014; Otto \& Hill 2017; Otto \& Hill 2018). Males of many species also have enlarged, setose third legs, which are used in the complex display performance. Following recent field work in south-western Western Australia, members of the Project Maratus team (see https://www.facebook.com/ projectmaratus/) collected an undescribed species, $M$. fletcheri sp. nov., and extended the known distribution for M. madelineae Waldock, 2014. An additional species, $M$. harveyi sp. nov. is also described here.

\section{MATERIAL AND METHODS}

The material examined for this study is lodged in the Western Australian Museum, Perth, Australia (WAM). Specimens were preserved and described in $75 \%$ or 95\% ethanol, illuminated with Halogen lights, and illustrated with the abdomen and cephalothorax in a flat, horizontal position. Female genitalia were examined by dissecting epigynes from the abdomen and clearing them in $10 \%$ lactic acid at room temperature for several days. Epigynes were mounted in glycerol and illustrated with a camera lucida on a Leica DM 2500 compound microscope. Other drawings and measurements were made using a Leica MZ6 or Leica MZ16A stereo microscope and Leica Application Suite V3.8.0 from Leica Microsystems Ltd. Terminology for male and female genitalia follow Żabka (1987).

\section{TAXONOMY}

\section{Family Salticidae Blackwall, 1841}

Subfamily Salticinae Blackwall, 1841

\section{Genus Maratus Karsch, 1878}

Maratus Karsch, 1878: 27.

\section{TYPE SPECIES}

Maratus amabilis Karsch, 1878, by subsequent designation of Bonnet (1957: 2713).

\section{COMPOSITION}

Maratus is considered a member of the tribe Euophryni, subfamily Salticinae following Maddison (2015). As of November 2020, there were 97 named species and one subspecies of Maratus recognised (World Spider Catalogue 2020). 


\section{REMARKS}

The species-specific (and often spectacular) colour patterns on male Maratus species are the result of specialised short squamous setae, which cover the dorsal abdominal scute and parts of the dorsal carapace (Figures 6, 15). These setae reflect different colours, depending on the angle of orientation and reflect different colour spectra on different parts of the abdomen (Figures 6, 15). When preserved in alcohol, the vibrancy of the colours may be reduced, e.g. squamous setae that appear red in life will show as orangey to light brown over time. To standardise the colour pattern descriptions, the specimens were viewed under Halogen lights with the abdomen and cephalothorax in a flat, horizontal position. This combination leads to the squamous setae reflecting colours as rose-gold, orangey, brown and pink. When the abdomen is raised to a vertical position the rose-gold squamous setae reflect as electric blue; in life these rose-gold coloured areas are blue/green. In addition, where available, digital images of live males of $M$. fletcheri sp. nov. and $M$. harveyi sp. nov. have been included.

\section{Maratus fletcheri Waldock, sp. nov.}

\author{
Fletcher's Peacock Spider
}

Figures 1-9, 19

urn:Isid:zoobank.org:act:ED8CAC05-0E68-4DC4-A4006C48DE1FD910

\section{MATERIAL EXAMINED}

\section{Holotype}

Australia: Western Australia: ô, c. $11 \mathrm{~km} \mathrm{NE}$. of Cowaramup on Jindong-Treeton Road, 3348'35"S, 115²'55"E, 18 September 2016, A. Fletcher, M. Doe, M. Duncan (WAM T140702).

\section{Paratypes}

Australia: Western Australia: 3 กิ, 3 o, Treeton, W. side of Smith Road, 334ㅇ' $36^{\prime \prime S}, 115^{\circ} 13^{\prime} 41^{\prime \prime E}, 17$ September 2016, A. Fletcher, M. Doe, M. Duncan (WAM T146586-91).

\section{DIAGNOSIS}

Males of Maratus fletcheri may be distinguished from all other known species in the Maratus vespa speciesgroup (Otto \& Hill 2018) except $M$. harveyi sp. nov. by the absence of red patches or stripes in the centre of the optical region. In common with all other species in the $M$. vespa group, the abdominal pattern in males consists of two regions with distinctively different colouration and patterning: $M$. fletcheri resembles that of $M$. vespa Otto \& Hill, 2016, M. icarus Otto \& Hill, 2019a and $M$. cristatus Otto \& Hill, 2017 by the presence of blue/green and red stripes in the anterior half of abdomen (Figure 6 ), but these stripes are arranged differently for each of these species and in $M$. fletcheri the red stripes continue as tan and black stripes on the posterior half. The third legs of $M$. fletcheri, which have dense brown and black brushes on all segments and white bristles in clumps on the femur, patella and tibia (Figures 3,6), resemble $M$. vespa, but the brushes on the femur are brown instead of white (Figure 6).

Females of $M$. fletcheri differ from all other known Maratus species except M. madelineae Waldock, 2014 and M. karrie Waldock, 2013 by the swollen proximal receivers that abut at the median guide (Figures 8, 9), and by the enlarged intermediate canals abutting at the median guide. The fossae are laterally compressed compared to all other known Maratus species.

\section{DESCRIPTION}

\section{Male (holotype)}

Cephalothorax black to dark brown with white setae bordering lateral edges. Dense mat of light pale blue squamous setae covering ocular region, small patches of orange setae posterior to ALE and adjacent to PLE; elongate orange patches of setae extending from posterior edge of ocular area towards AME; tuft of white setae between PME and PLE; oval patch of white setae posterior to fovea. Anterior eyes fringed with creamy setae along dorsal margin, ALE surrounded by orangey setae; rest of cephalothorax lightly covered with scattered short white setae and brown bristles (Figures 1, 6). Clypeus golden yellow, chelicerae dark brown, cream distally. Maxillae light cream, labium dark grey with cream edge. Sternum dark grey.

Venter of abdomen dark yellow with greyish smudges in centre and laterally; spinnerets dark grey. Dorsal abdominal scute developed as short lateral flaps which do not meet across the venter when relaxed; the lateral extensions exhibit a continuation of the posterior half of the dorsal pattern. Posterior half of dorsum with greyish squamous setae with lighter grey bands outlined with narrow lines of short black setae (Figures 1, 6). Anterior half of dorsal abdomen with red-orange squamous setae as six bands extending lengthwise to anterior edge, alternating with bands of greenishblue squamous setae (Figures 1,6) with black setae that continue as extensions of the anterior red bands; posterior edged with short black setae interspersed with small patches of greenish-blue squamous setae. Black and grey longitudinal bands continue onto lateral flaps with two circular patches of greyish squamous setae surrounded by short black/electric blue setae distally and plumose electric-blue setae along distal edge of flaps (Figure 2). Anterior corner of flap with very long dark grey and cream bristles; posterior border of flaps with short black squamous setae interspersed with orangey-red short squamous setae. Up to four long plumose black/electric blue iridescent setae spaced along posterior border of flaps (Figures 2, 6). Dorsal scute not covering spinnerets, this area lacking squamous setae and dark grey with short brown setae; creamy strip of 
short setae merging with white patch at tip of abdomen (Figures 1,6).

Legs I, II and IV: proximal femora cream dorsoanteriorly with dark grey patches ventro-posteriorly; patellae, tibiae, metatarsi and tarsi tan with grey bands at joints; covered with dense short white setae interspersed with black bristles. Leg III: dorsal femur cream, rest dark grey, patella tibia and metatarsus dark yellow with greyish patches at joints; tarsus cream. Femur, patella and tibia with thick brush of long setae dorso-ventrally; dorsal femur and patella with white brush setae; brush setae on tibia greyish, becoming creamy distally (Figures 3, 6); metatarsus with greyish brush setae ventrally; tarsus with thick short white setae on all surfaces and longer white setae at tip, covering claws (Figures 3, 6).

Pedipalp yellow with greyish patches on proximal segments. Tibial apophysis narrow, straight (Figure 5). Cymbium, dorsal tibia and dorsal patella densely covered with long creamy setae, a single very long black seta on dorsal pedipalpal patella; tibia and cymbium with a few long creamy and brown setae on ventral side just under tegulum. Embolus with broad tip and conductor closely aligned with embolus into tight coil,
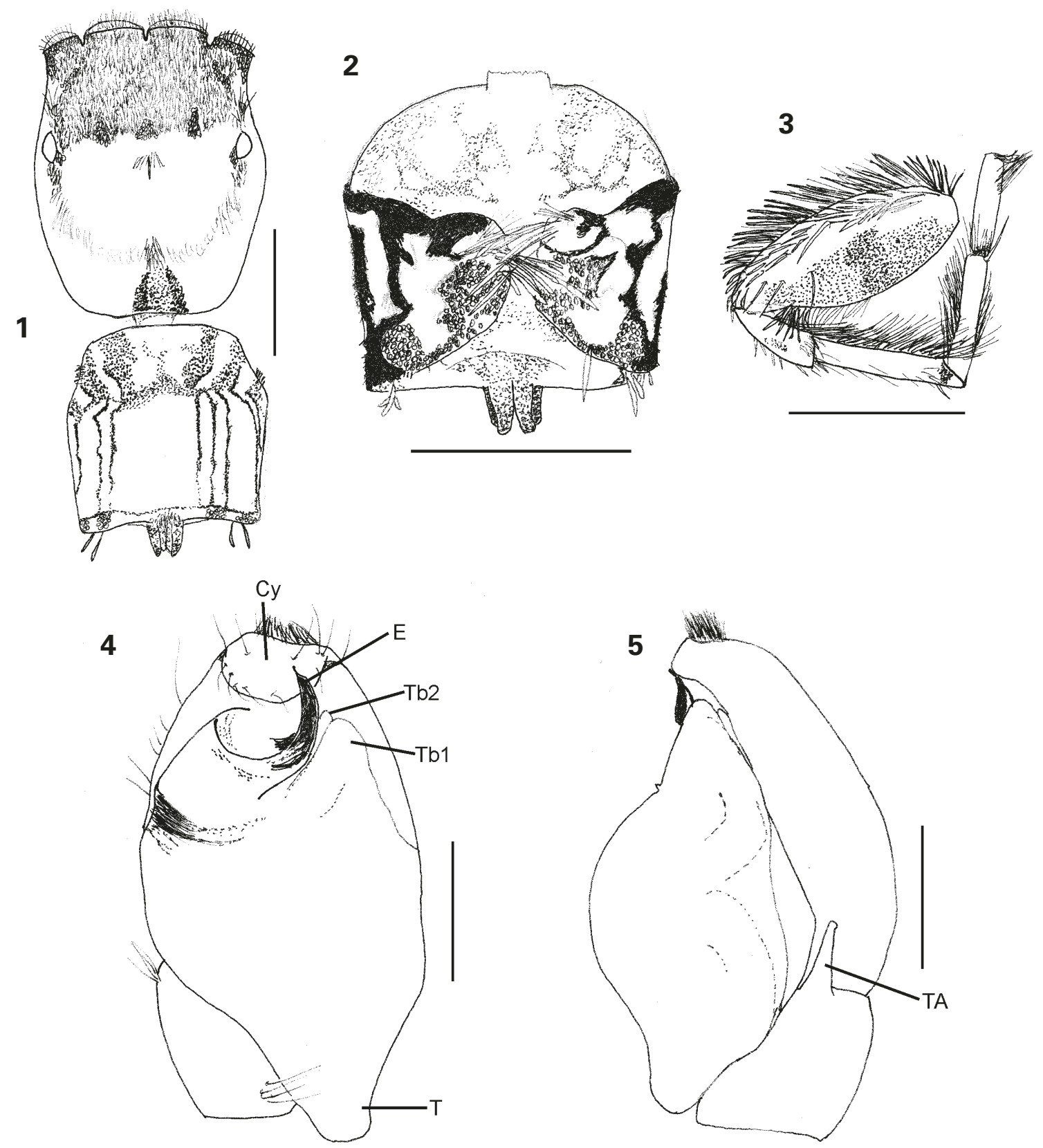

FIGURES 1-5 Maratus fletcheri sp. nov., male holotype (WAM T40702): 1) cephalothorax and abdomen, dorsal view; 2) abdomen, ventral view (abdominal flaps folded); 3) left leg III, retrolateral view; 4) left pedipalp, ventral view; 5) left pedipalp, retrolateral view. Scale lines = $1 \mathrm{~mm}$ (Figures 1-3), $0.3 \mathrm{~mm}$ (Figures 4-5). $\mathrm{Cy}=$ cymbium; $\mathrm{E}=$ embolus; $\mathrm{T}$ = tegulum; TA = tibial apophysis; TB1-2 = tegular bulges 1-2. 


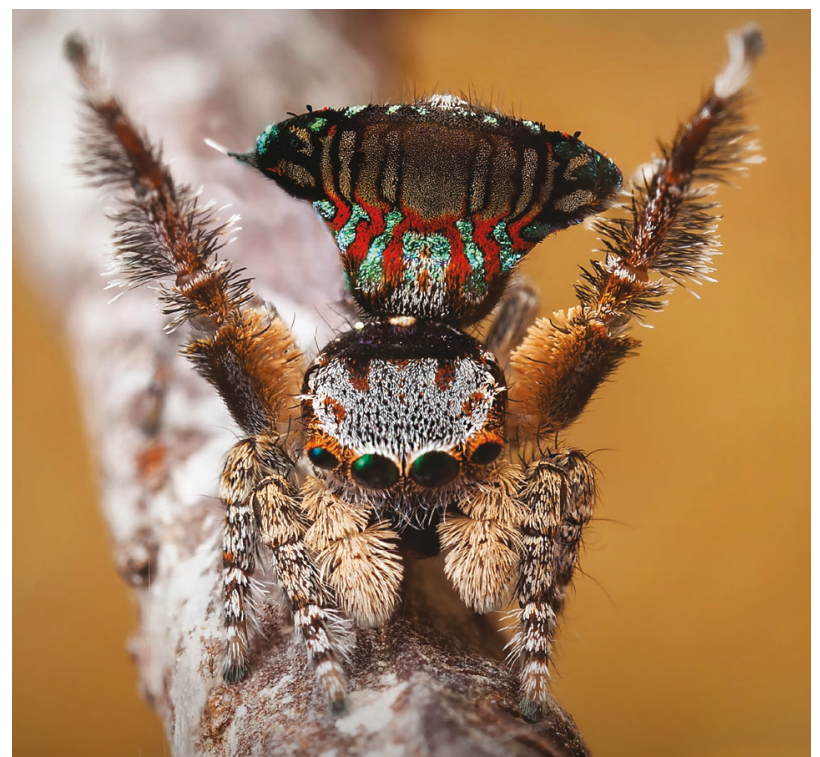

FIGURE 6

Maratus fletcheri sp. nov., photograph of male with extended abdominal flaps. (Image courtesy A. Fletcher.) tucked under tip of cymbium; tegulum with two bulges adjacent to embolus (Figure 4).

\section{Female (paratype, WAM T146591)}

Ocular region black, densely covered with short creamy and black setae; black setae concentrated in area around PLE, extending towards centre and AME; rest of cephalothorax golden-yellow with grey to light grey patches and scattered creamy and black setae. Posterior to ocular area and fovea, yellow with broad grey patch posterior to fovea; two broad grey bands extend to posterior margin with yellow central strip (Figure 7). Sides of cephalothorax yellow with small light grey patches. Clypeus light yellow; chelicerae, maxillae, labium light yellow with white border. Sternum cream with light grey edging.

Abdomen oval with tan dorsal sigilla and black bristles scattered amongst brown and creamy setae; most of dorsum covered in dark grey to black diffuse pattern on creamy background; pattern darkens and narrows to point above spinnerets (Figure 7). Venter of abdomen cream, with small grey spots in longitudinal rows, larger
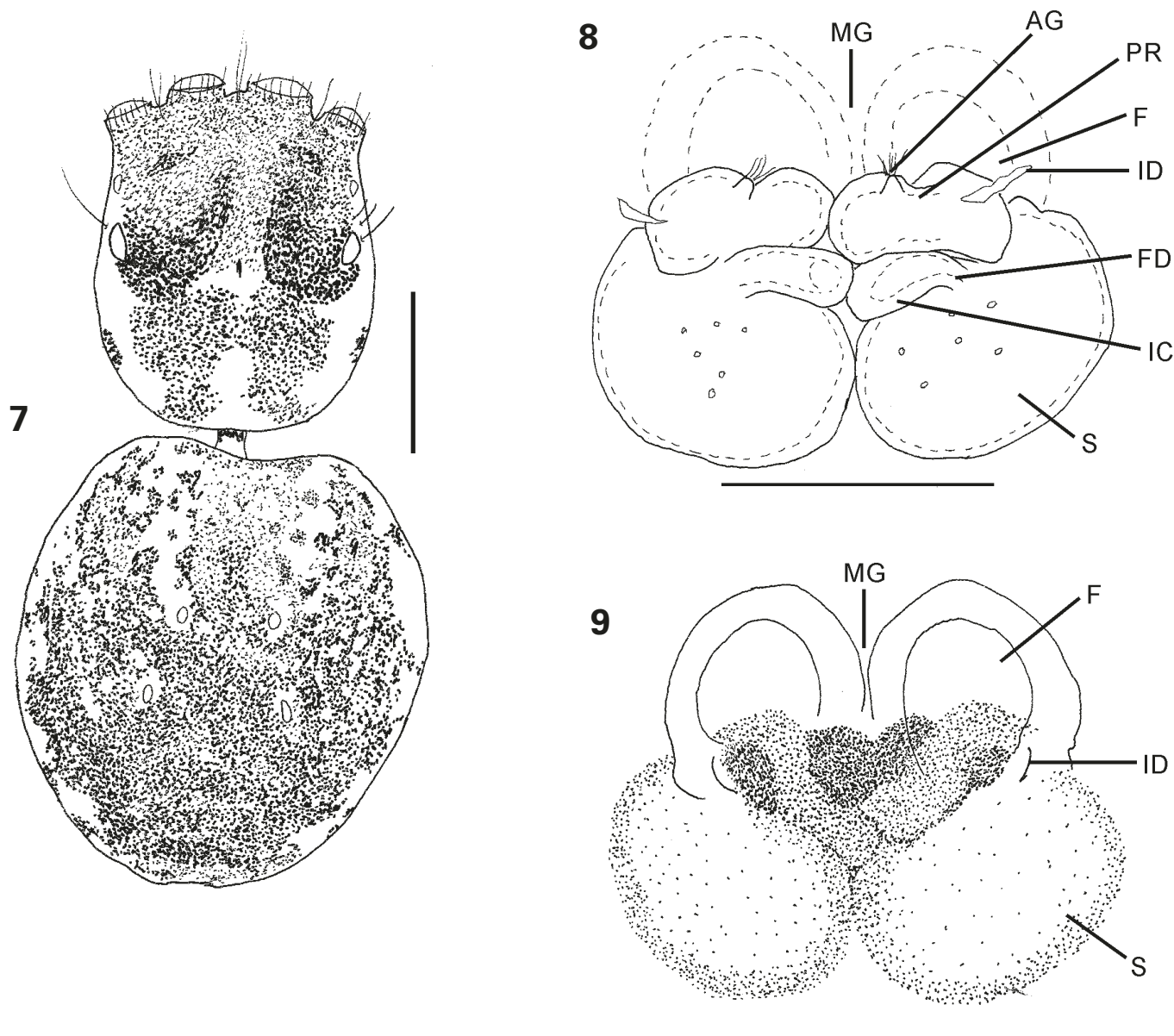

FIGURES 7-9 Maratus fletcheri sp. nov., female paratype (WAM T146591): 7) cephalothorax and abdomen, dorsal view; 8) cleared epigyne, dorsal view; 9) epigyne, ventral view. Scale lines = $1 \mathrm{~mm}$ (Figure 7), $0.25 \mathrm{~mm}$ (Figures 8-9). $A G=$ accessory gland; $F=$ fossa; $F D=$ fertilisation duct; $I C=$ intermediate canal; ID = insemination duct; $M G=$ median guide; $P R=$ proximal receiver; $S=$ spermatheca. 
elongate spots at edges. Ventral spinnerets cream, dorsal pair, dark grey.

Femora and patellae of legs yellow, no markings dorsally, grey patches at joints and mid-way of femora; tibiae, metatarsi and tarsi yellowy with grey bands at joints.

Proximal receivers of epigyne large and abutting each other at median guide. Openings of intermediate canals situated at centre of anterior margin of spermathecae, abutting at median guide. Insemination ducts opening on lower lateral border of fossa, over lateral coil of proximal receiver; fossae laterally compressed ovals (Figures 8-9).

\section{Dimensions ( $\mathrm{mm}$ )}

Holotype $\delta$ (paratype 9 , WAM T146591): total length (excluding chelicerae) 3.60 (4.96). Carapace length 2.12 (2.13). Abdomen length 1.47 (2.64). Leg I: femur 0.95 (0.84), patella $0.63(0.61)$, tibia $0.62(0.56)$, metatarsus 0.43 (0.41), tarsus 0.35 (0.39). Leg II: femur 0.87 (0.88), patella $0.60(0.52)$, tibia $0.55(0.51)$, metatarsus 0.41 (0.47), tarsus 0.31 (0.38). Leg III: femur 1.37 (1.34), patella $0.53(0.71)$, tibia $0.84(0.82)$, metatarsus 0.66 (0.74), tarsus 0.55 (0.54). Leg IV: femur 0.98 (1.24), patella $0.43(0.49)$, tibia $0.72(0.63)$, metatarsus 0.72 (0.81), tarsus $0.46(0.49)$. Legs, relative lengths: III: IV: I: II (III: IV: I: II).

\section{DISTRIBUTION}

Maratus fletcheri has only been recorded from near Treeton, south-western Australia (Figure 19), in Banksia, jarrah (Eucalyptus marginata) and marri (Corymbia calophylla) woodland.

\section{MATING BEHAVIOUR}

Courtship behaviour has been observed for five male and female pairs (see https://www.youtube.com/ watch?v=Ly3AYL7cktI by A. Fletcher, M. Duncan \& M. Doe, accessed 30 November 2020). The male raises one or other third leg, which attracts the female's attention. Once the female is watching, the male raises the other third leg as well as raising and expanding the abdominal fan centrally. The fan is quickly shaken from side to side and lowered then raised and shaken again. Then the male rotates the fan to one side (closing the extended flap on the opposite side) and extends the plumose setae (elongated setae on the tip of the lateral flaps).

The female appears to be attracted to these elongate setae as they emerge at the side of the male vibrating at the tip of the extended lateral flap. The female's focus swaps from the left and right sides as the male 'hides' these setae behind the setose third legs. The male holds this pose for a short time and then changes sides, rotating the fan to the opposite side and revealing the plumose setae again, the female closely mirrors these changes from side to side as evidenced by movements of the cephalothorax. This behaviour is not unlike teasing a cat with a moving object. This 'teasing' will continue for up to three minutes with both the male and female moving forwards and backwards, closer and farther from each other.

\section{ETYMOLOGY}

The specific epithet is a patronym in honour of Adam Fletcher, photographer and collector, and founding member of Project Maratus.

\section{Maratus harveyi Waldock, sp. nov.}

\author{
Harvey's Peacock Spider
}

Figures 10-18, 19

urn:Isid:zoobank.org:act:6737D2ED-7C37-4F3F-965C628E39F1016F

\section{MATERIAL EXAMINED}

Holotype

Australia: Western Australia: đิ, Barrabup Road, W. of Nannup, 3358'52.6"S, 11544'58.0"E, 28 October 2018, C. O’Toole, P. Irvine (WAM T59140).

\section{Paratypes}

Australia: Western Australia: $1 \hat{\jmath}$, Barrabup Road, NW. of Nannup, 33 $58^{\prime} 53^{\prime \prime S}, 115^{\circ} 44^{\prime} 58^{\prime \prime}$ E, 21 October 2018, M.S. Harvey, M.E. Blosfelds (WAM T146690);


$115^{\circ} 44^{\prime} 58.0^{\prime \prime E}, 28$ October 2018, C. O’Toole, P. Irvine (WAM T59141, T59142); 1 9, Barrabup Road, W. of Nannup, 3358'52.6"S, 11544'58.0"E, 28 October 2018 (moulted to adult 30 November 2018), C. O'Toole, P. Irvine (WAM T59143).

\section{DIAGNOSIS}

Males of Maratus harveyi can be distinguished from all other known species in the Maratus vespa speciesgroup (Otto \& Hill, 2018) except M. fletcheri sp. nov., by the absence of red patches or stripes in the centre of the optical region of the cephalothorax. In common with all other species in the M. vespa group, the abdominal pattern in males consists of two regions with distinctively different colouration and patterning: while $M$. harveyi resembles M. icarus Otto \& Hill, 2019a and M. cristatus Otto \& Hill, 2017 by the presence of blue/green and red stripes in the anterior half of abdomen, $M$. harveyi differs as these stripes do not extend into the posterior half and there is a red band delimiting the pattern-less posterior half. The third legs of $M$. harveyi have dense light brown brushes on the femur, dense dark grey and black brushes on the patella, tibia and metatarsus, and white bristles in clumps on the patella and tibia (Figures 12, 15), resembling $M$. vespa Otto \& Hill but with the brushes on the femur brown instead of white.

Females of $M$. harveyi differ from all other known Maratus species except M. banyowla Otto \& Hill, 2019b and M. sarahae Waldock, 2013 by the tightly coiled proximal receivers that do not extend to the lateral borders of the fossae (Figures 17-18). 


\section{DESCRIPTION}

\section{Male (holotype)}

Cephalothorax black to dark brown with white setae bordering lateral edges. Dense mat of off-white squamous setae covering ocular region with light orange patches posterior to ALE; patch of white setae posterior to fovea. ALE fringed with orangey setae along dorsal margin, AME fringed with off-white setae along dorsal margin; patch of white setae posterior to PME, rest of cephalothorax lightly covered with scattered short brown setae and dark brown bristles (Figure 10). Clypeus pale yellow, chelicerae dark grey to black. Maxillae yellowish, labium dark grey with cream edge. Sternum dark grey.

Venter of abdomen pale yellow to white posteriorly with sparse greyish smudges in centre and laterally; spinnerets dark grey (Figure 11). Posterior half of dorsal abdominal scute developed as lateral flaps that fold around the sides of the abdomen but do not overlap on the venter; flaps exhibit a continuation of dorsal pattern (Figures 11, 15). Anterior half of dorsal abdomen with
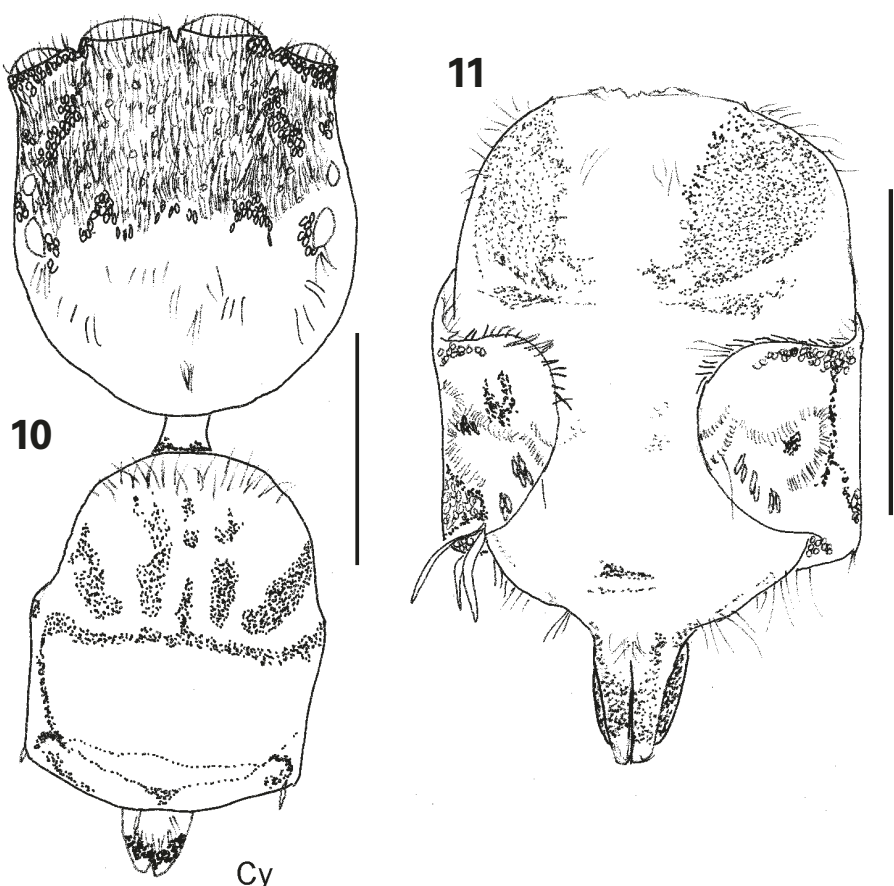

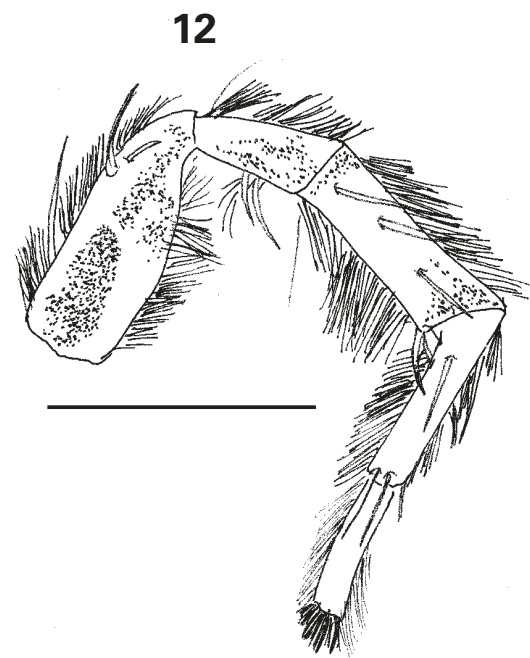

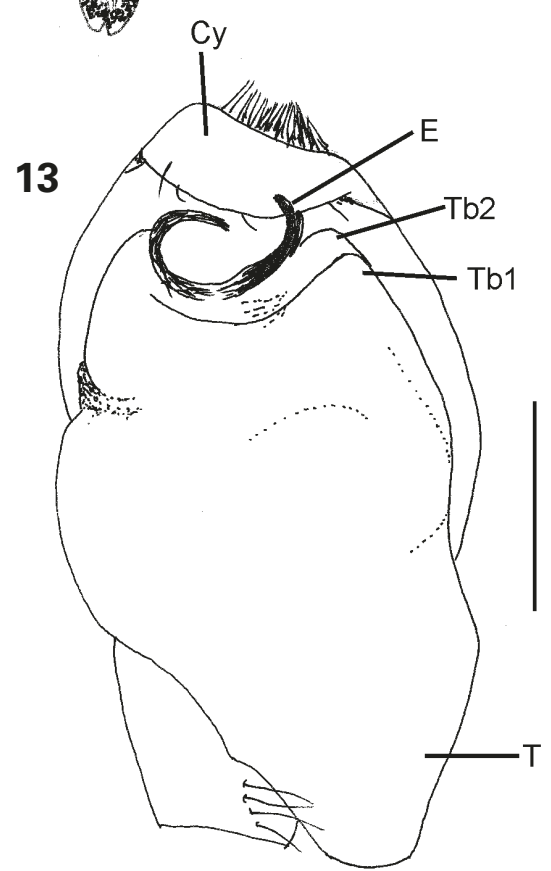

14



FIGURES 10-14 Maratus harveyi sp. nov. male holotype (WAM T59140): 10) cephalothorax and abdomen, dorsal view; 11) abdomen, ventral view (abdominal flaps folded); 12) left leg III, retrolateral view; 13) left pedipalp, ventral view; 14) left pedipalp, retrolateral view. Scale lines $=1 \mathrm{~mm}$ (Figures 10-12), $0.3 \mathrm{~mm}$ (Figures 13-14). Cy = cymbium; $\mathrm{E}=$ embolus; $\mathrm{T}=$ tegulum; TA = tibial apophysis; TB1-2 = tegular bulges 1-2. 
red-orange squamous setae as three central longitudinal bands and two oblique bands extending to anterior edge (five bands in total) with a narrow continuous stripe across dorsum extending onto lateral flaps; bluegreen squamous setae between bands (Figures 10, 15). Posterior half of dorsum grey, covered with very short squamous setae; with creamy crescent along posterior border, also covered with very short squamous setae; posterior edge of scute with border of alternating orange and blue-green squamous setae patches and scattered black squamous setae; several long plumose black/ electric-blue setae on each side of the postero-lateral edge of the flap (Figures 11, 15). Central white patch of setae above spinnerets (Figures 10, 15). Lateral flaps with purplish-blue 'eye' patch; border of short black squamous setae. Orange band from dorsum does not extend onto flap but follows main part of flap. Narrow border of orangey short squamous setae on anterior edge of flap; remainder of flap with grey and black/electricblue short squamous setae; black/electric-blue setae particularly dense along border of flap (Figure 11).

Legs I, II and IV: proximal half of femora cream dorso-anteriorly and rest dark grey with dark grey patches ventro-posteriorly; tibiae and patellae tan with dark grey bands at joints; metatarsi and tarsi cream, covered with dense short white setae interspersed with black bristles. Leg III: dorsal femur cream, rest dark grey dorsally and ventrally, patella, tibia and metatarsus tan; tibia brown; metatarsus tan, tarsus cream. Femur with dense brush of thick, short cream setae dorsally, long black/cream setae at distal joint ventrally; patella with thick brush of long black/cream setae ventrally, not as dense dorsally, small tufts of white setae above joint with metatarsus; thick brush of long black/cream setae continues onto ventral tibia and metatarsus, also dorsally but not as dense, particularly sparse on dorsal metatarsus (Figure 12); tarsus with thick, short white setae on all surfaces and longer white setae at tip, covering claws (Figure 12).

Pedipalp creamy yellow. Tibial apophysis narrow, straight (Figure 14). Cymbium, dorsal tibia and dorsal patella densely covered with long white setae, a single very long black seta on dorsal pedipalpal patella; tibia and cymbium with a few long creamy setae on ventral side just under tegulum. Embolus with broad tip and conductor closely aligned with embolus into tight coil, tucked under tip of cymbium; tegulum with two bulges adjacent to embolus (Figure 13).

\section{Female (paratype, WAM T59143)}

Ocular region black, densely covered with short creamy setae and scattered black long setae, rest of

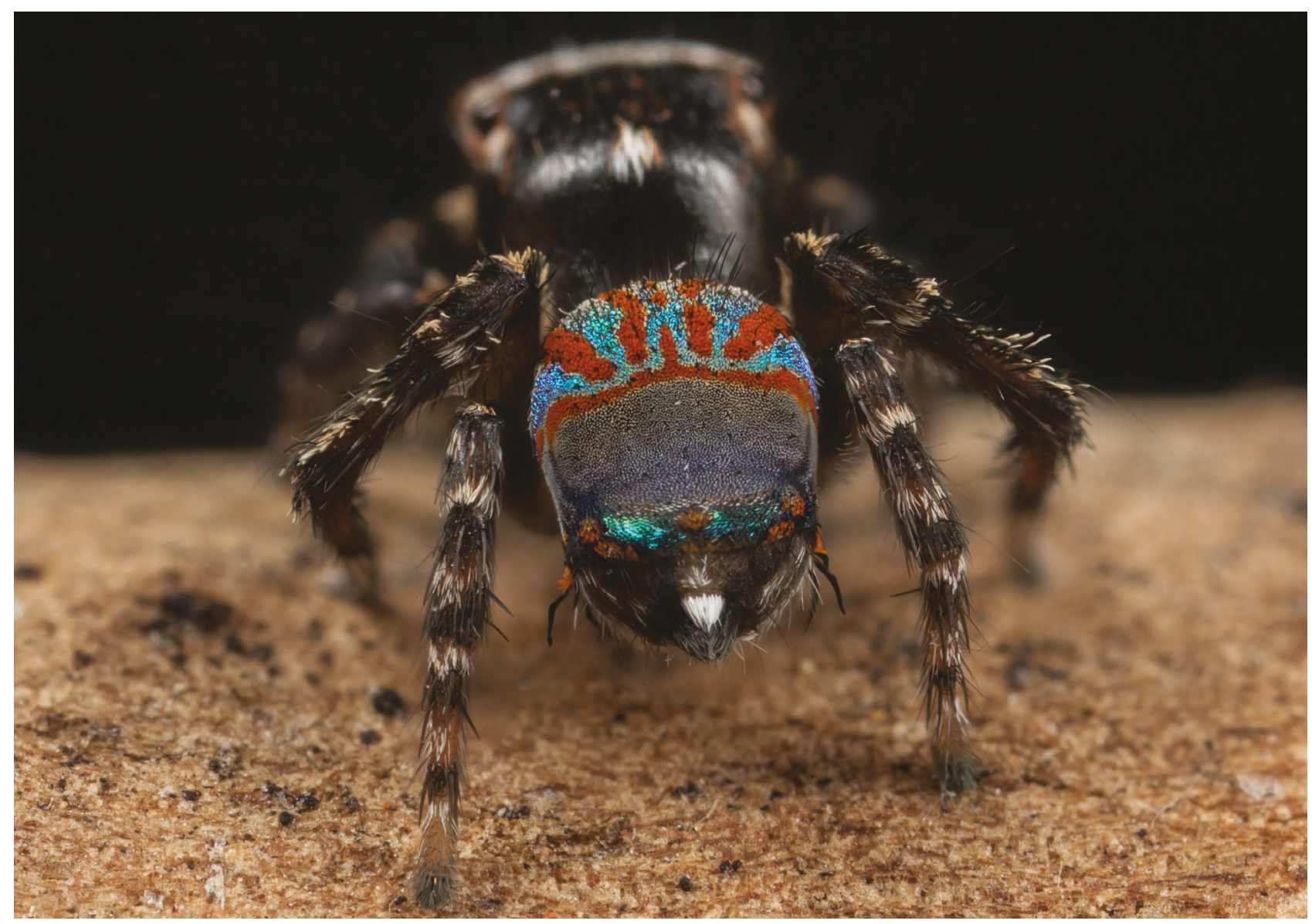


16

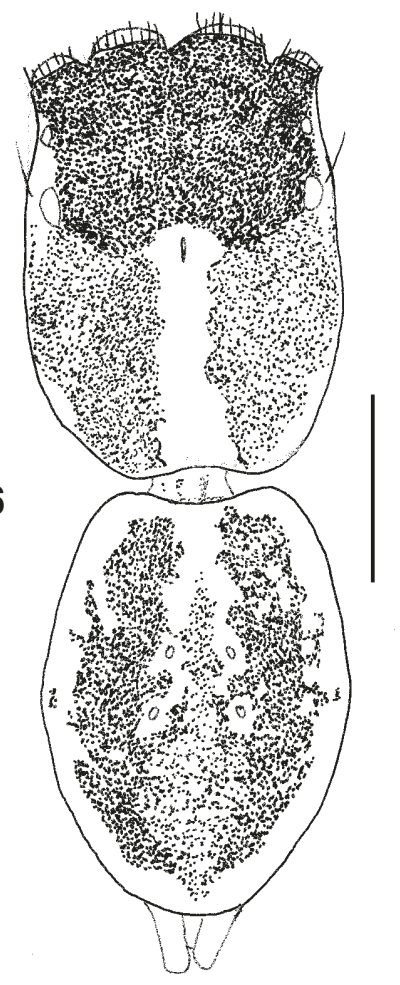

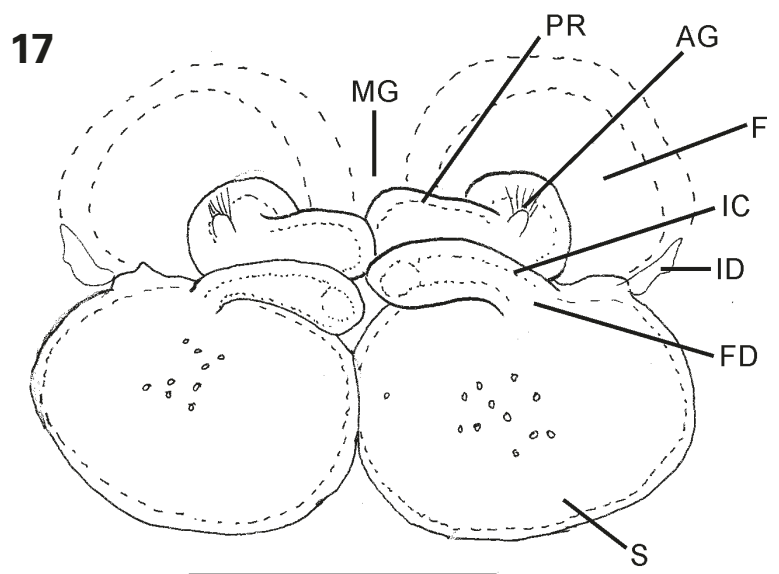

18

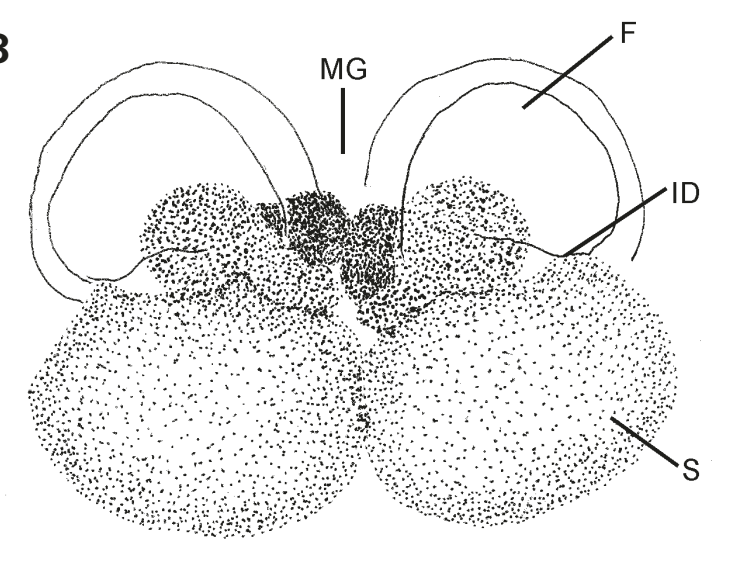

FIGURES 16-18 Maratus harveyi sp. nov. female paratype (WAM T59143): 16) cephalothorax and abdomen, dorsal view; 17) cleared epigyne, dorsal view; 18) epigyne, ventral view. Scale lines $=1 \mathrm{~mm}$ (Figure 16), $0.25 \mathrm{~mm}$ (Figures 17-18). $A G=$ accessory gland; $F=$ fossa; $F D=$ fertilisation duct; $I C=$ intermediate canal; $I D=$ insemination duct; $M G=$ median guide; $P R=$ proximal receiver; $S=$ spermatheca.

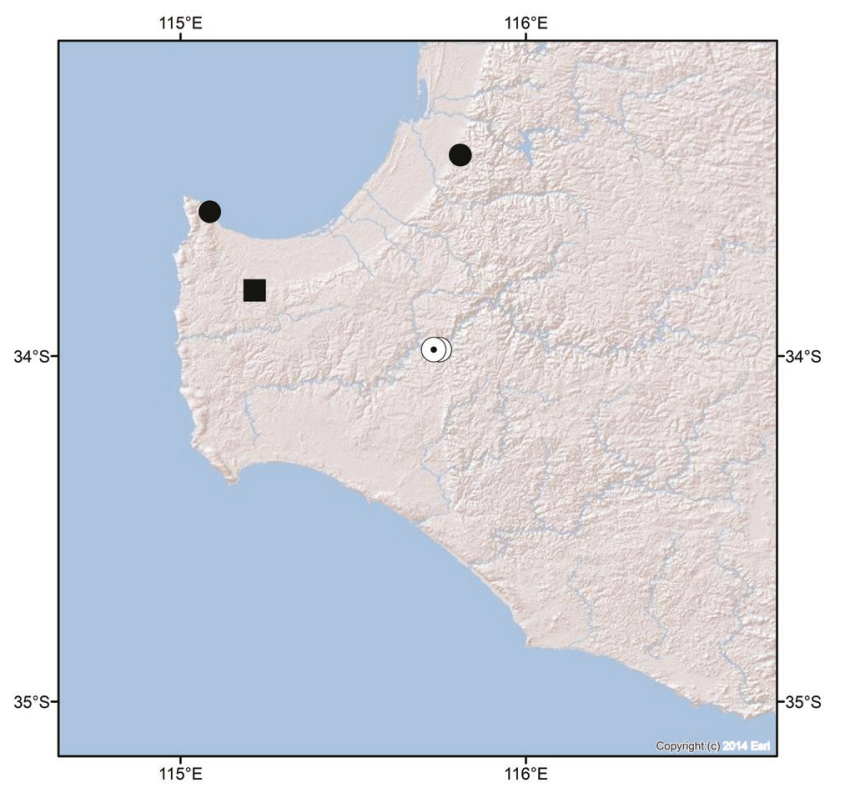

FIGURE 19 Map of collection localities of Maratus in south-western Western Australia:

M. fletcherisp. nov. (solid square); M. harveyisp. nov. (open circle); M. madelineae (solid circle). cephalothorax dark grey to black grading to light grey with a pale yellow band with short white setae. A broad pale yellowish strip with short white setae extends from anterior of fovea to posterior edge (Figure 16). Clypeus cream; chelicerae yellow with light grey patches, maxillae, labium cream. Sternum cream with light grey shading.

Abdomen oval with light tan dorsal sigilla and black bristles scattered amongst light brown setae; most of dorsum covered in dark grey to black patch on light cream background; patch grades to pale grey at spinnerets (Figure 16), and central patch is divided by a light grey band which extends from anterior to posterior of abdomen; edges of dorsum pale yellow with a few scattered light grey patches. Venter of abdomen light cream, with small scattered patches of grey and dark grey stripes at edges. Dorsal spinnerets cream, ventral pair cream with light grey patches.

Femora light cream with dark grey patches posterolaterally on all legs, grey patches become bands ventrally on legs III and IV; patellae creamy, no markings; tibiae of all legs creamy with greyish patches proximally and distally; rest of leg segments without banding. 
Proximal receivers of epigyne tightly coiled, not extending across spermathecae to lateral edges of fossae; slightly swollen at median guide, not separated, right proximal receiver sitting ventral to left proximal receiver. Intermediate canals open at anterior margin of spermathecae from somewhat elongate tubules that extend across median guide. Insemination ducts opening at centre of posterior border of fossae. Fossae anteroposteriorly compressed ovals (Figures 17-18).

\section{Dimensions ( $\mathrm{mm}$ )}

Holotype $\widehat{\delta}$ (paratype $\propto$, WAM T59143): total length (excluding chelicerae) 3.82 (4.67). Carapace length 1.84 (2.25). Abdomen length 1.66 (2.17). Leg I: femur 0.84 (0.74), patella $0.46(0.45)$, tibia $0.53(0.49)$, metatarsus 0.39 (0.44), tarsus 0.35 (0.39). Leg II: femur 0.79 (0.91), patella $0.41(0.48)$, tibia $0.43(0.47)$, metatarsus 0.37 (0.49), tarsus 0.31 (0.40). Leg III: femur 1.31 (1.61), patella $0.50(0.69)$, tibia $0.69(0.84)$, metatarsus 0.71 (0.85), tarsus 0.52 (0.48). Leg IV: femur 1.00 (1.30), patella $0.47(0.36)$, tibia $0.60(0.45)$, metatarsus 0.63 (0.96), tarsus $0.41(0.51)$. Legs, relative lengths: III: IV: I: II (III: IV: II: I).

\section{DISTRIBUTION}

Maratus harveyi has only been recorded from the vicinity of Barrabup Road, Nannup, south-western Australia (Figure 19).

\section{ETYMOLOGY}

The specific epithet is in honour of Mark Harvey, senior curator of the Arachnology collection of the Western Australian Museum and co-collector of the first known specimen of this species.

\section{Maratus madelineae Waldock, 2014}

\section{Madeline's Peacock Spider}

(Figure 19)

Maratus madelineae Waldock, 2014: 150, figures 1-10.

\section{MATERIAL EXAMINED}

Australia: Western Australia: 3 ô, Meelup Regional Park, c. $4 \mathrm{~km} \mathrm{NW}$. of Dunsborough, 3334'56"S, $115^{\circ} 05^{\prime} 08^{\prime \prime E}, 17$ September 2016, A. Fletcher, M. Doe, M. Duncan (WAM T146592-4); 2 \%, Meelup Regional Park, c. $4 \mathrm{~km} \mathrm{NW}$. of Dunsborough, 3334'56"S, $115^{\circ} 05^{\prime} 08^{\prime \prime E}, 17$ September 2016, P. Irvine (WAM T146595-6).

\section{DISTRIBUTION}

Maratus madelineae has previously been recorded from Dardanup National Park (Waldock 2014), and the new records extend the known distribution of the species by c. $70 \mathrm{~km} \mathrm{SW}$. of the type locality.

\section{ACKNOWLEDGEMENTS}

Many thanks to Mark Harvey for providing the map. We also appreciate the helpful suggestions from Dr Michael Rix and Joseph Shubert.

\section{REFERENCES}

Bonnet, P. (1957). Bibliographia Araneorum 2(3). Douladoure: Toulouse.

Karsch, F. (1878). Diagnoses Attoidarum aliquot novarum Novae Hollandiae collectionis Musei zoologici Berolinensis. Mitteilungen des Münchener Entomologischen Verein, München 2: 22-32.

Maddison, W.P. (2015). A phylogenetic classification of jumping spiders (Salticidae). Journal of Arachnology 43(3): 231-292. doi: 10.1636/arac-43-03-231-292.

Otto, J.C. and Hill, D.E. (2016). Seven new peacock spiders from Western Australia and South Australia (Araneae: Salticidae: Euophryini: Maratus). Peckhamia 141.1: 1-101.

Otto, J.C. and Hill, D.E. (2017). Five new peacock spiders from Western Australia (Araneae: Salticidae: Euophryini: Maratus Karsch, 1878). Peckhamia 152.1: 1-97.

Otto, J.C. and Hill, D.E. (2018). Two new peacock spiders in the vespa group from Western Australia (Araneae: Salticidae: Euophryini: Maratus). Peckhamia 168.1: 1-82.

Otto, J.C. and Hill, D.E. (2019a). Three new peacock spiders from the southeast and southwest of Australia (Araneae: Salticidae: Euophryini: Maratus). Peckhamia 189.1: 1-77.

Otto, J.C. and Hill, D.E. (2019b). Maratus banyowla, a new peacock spider in the personatus group from Western Australia (Araneae: Salticidae: Euophryini). Peckhamia 195.1: $1-23$.

Waldock, J.M. (2013). A review of the peacock spiders of the Maratus mungaich species-group (Araneae: Salticidae), with descriptions of four new species. Records of the Western Australian Museum 28(1): 66-81. doi: 10.18195/issn.03123162.28(1).2013.066-081.

Waldock, J.M. (2014). Two new species of peacock spider of the Maratus mungaich species-group (Araneae: Salticidae) from south-western Australia. Records of the Western Australian Museum 29(2): 149-158. doi: 10.18195/issn.03123162.29(2).2014.149-158.

World Spider Catalog (2020). World Spider Catalog. Version 21.5. Natural History Museum Bern, online at http://wsc. nmbe.ch, accessed on 30 November 2020.

Żabka, M. (1987). Salticidae (Araneae) of Oriental, Australian and Pacific Regions, II. Genera Lycidas and Maratus. Annales Zoologici 40: 451-482.

MANUSCRIPT RECEIVED 8 APRIL 2020; ACCEPTED 11 JULY 2020. 